\title{
VHF COMMUNICATION ANTENNA INTEGRATED INTO AN AIRCRAFT WINGLET
}

EMUS 2020

\section{MARTÍNEZ-VÁZQUEZ ${ }^{1}$, Z. ŘEZNÍČEK ${ }^{2}$, S. STEEGER $^{3}$, P. VRCHOTA ${ }^{4}$, V. LUNGAHO}

\author{
${ }^{1}$ IMST, GmbH \\ Carl-Friedrich-Gauß-Str. 2-4 \\ 47475 Kamp-Lintfort, Germany \\ e-mail: Martinez@imst.de,www.www.imst.com \\ ${ }^{2}$ Evektor, spol. s r.o. \\ Engineer. Services Division, Letecká 1008 \\ 68604 Kunovice, Czech Republic \\ email: zreznicek@evektor.cz, www.evektor.cz \\ ${ }^{3}$ INVENT, GmbH \\ Christian-Pommer-Straße 34 \\ 38112 Braunschweig, Germany \\ email: Stefan.Steeger@invent-gmbh.de, www.invent-gmbh.de \\ ${ }^{4}$ Czech Aerospace Research Centre (VZLU) \\ Beranovych 130 \\ 19905 Prague, Czech Republic \\ email:vrchota@vzlu.cz, www.vzlu.cz \\ ${ }^{5}$ Trackwise Designs plc \\ 1 Ashvale Alexandra Way, Ashchurch, Tewkesbury \\ Gloucestershire, England \\ email: victor.lungaho@ trackwise.co.uk,www.trackwise.co.uk
}

Key words: VHF antenna, Computational Electromagnetics, Winglet, Aircraft

\begin{abstract}
The article is discussing the final design of a VHF communication antenna integrated in a composite winglet of the EV-55 small transport aircraft. The antenna is designed to operate in the VHF band reserved for civil aviation, $117.975-137 \mathrm{MHz}$ with optimal VSWR below 2.5. Compared with a standard vertically polarized monopole antenna, the radiation pattern in the horizontal plane shall not be down more than $6 \mathrm{~dB}$ and vary more than $6 \mathrm{~dB}[2]$.
\end{abstract}

\section{INTRODUCTION}

Designers of modern winglets are trying to introduce more functionalities into a winglet structure nowadays. This is also the case for the ACASIAS project [1], where one of the systems to be developed is a VHF antenna integrated into the winglet.

Such a design usually represents a complex and multidisciplinary task, especially due to specific technical trade-offs and bottlenecks originating from the following three distinctive engineering areas: aerodynamics, stress analysis and electromagnetics [3]. 
From the antenna point of view, several challenges have been faced during the design: final physical dimensions of the winglet and the VHF antenna are relatively small compared to target wavelengths $(\lambda \approx 2-2.5 \mathrm{~m})$. Integration of the antenna into such a small area may easily become a challenging task focused on finding more spatially effective solutions without sacrificing necessary performance. In addition, some requirements specified for airborne VHF systems are in favour of standard monopole-like solutions installed on top or bottom of an airplane fuselage, where omnidirectional radiation pattern is preferred in horizontal plane. Such a requirement can be discriminating for the antenna situated at the tip of a wing due to obstructions caused by an airplane. In addition, winglet parts tend to attract lightning strikes more easily. Therefore, more stringent protection of the antenna and all related systems should be taken into account.

\section{ANTENNA DESIGN}

\subsection{Winglet with integrated notch antenna}

The final geometry of the winglet is depicted on Figure 1. The chosen concept is a notch antenna [4] printed on a thin, flexible PCB sandwiched in the foam filling of the winglet. The open side is tapered for broadband matching. The outer skin of the winglet is made out of Carbon Fibre Reinforced Plastic (CFRP) with an expanded copper foil at the external layer, so that a Glass Fibre Reinforced Plastic (GFRP) "window" was scarfed on the winglet skin to allow the antenna to radiate.

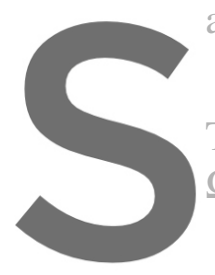

All simulation mo The protected CFRP $\Omega / \mathrm{sq}$ at $100 \mathrm{MHz}$ ) anc
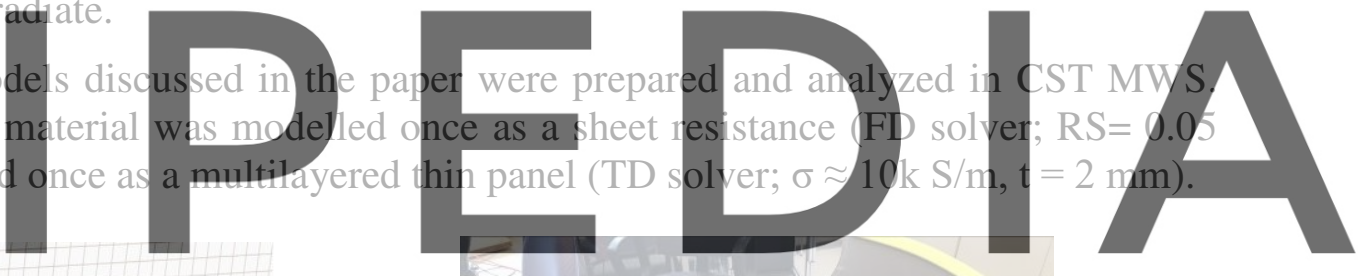

Register for Gfre
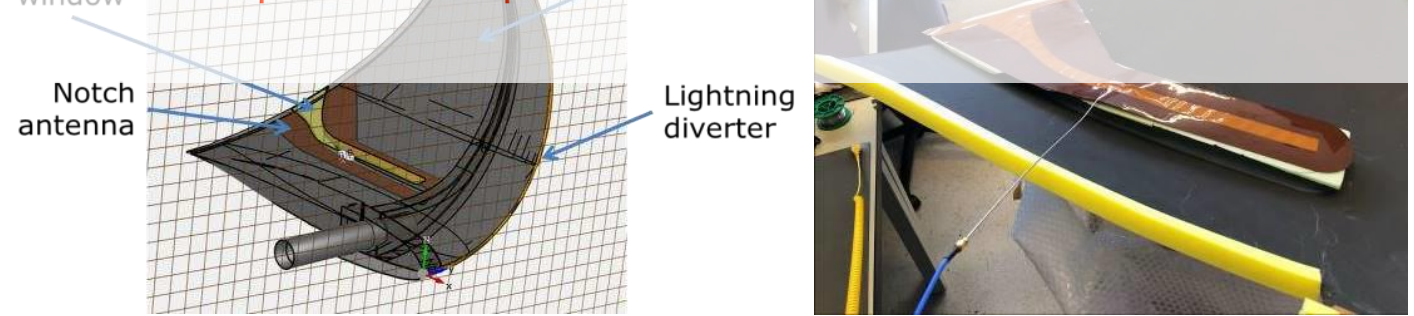

Figure 1: EV55 winglet with integrated notch antenna: structural model (left) and prototype (right)

\subsection{Preliminary measurements}

A half-opened model of the winglet structure (Figure 1) was used for a preliminary characterization of the integrated notch antenna's properties. During the measurement, a semirigid coaxial cable has been used as a feeding line and the final position of the feeding port was $240 \mathrm{~mm}$ from the end of the notch. The measured and simulated reflection coefficients for two different feeding points and computational methods are presented in Figure 2. 

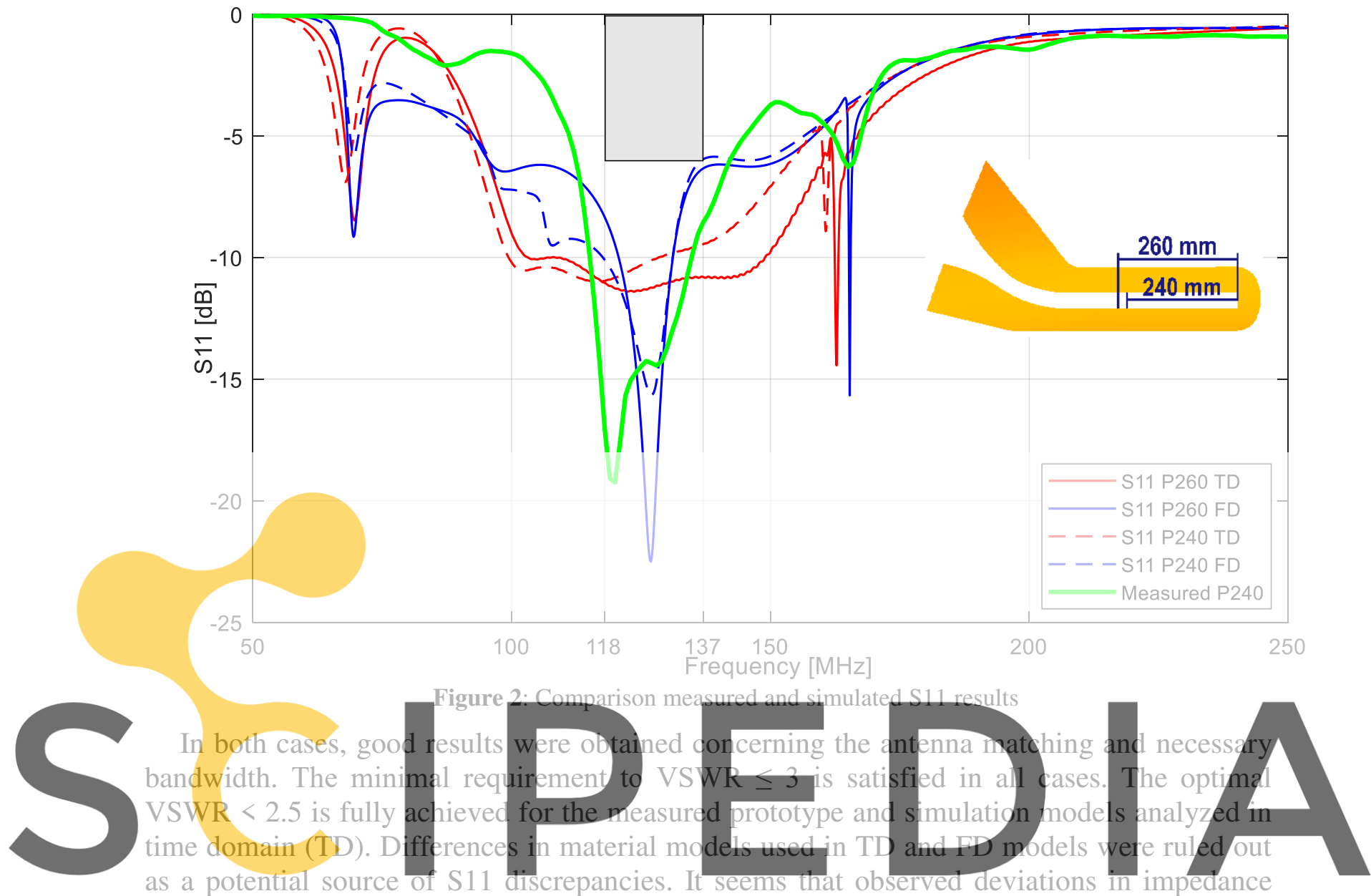

as a potential source of S11 discrepancies. It seems that observed deviations in impedance behavior of the antenna are directly related with different computational methods and used

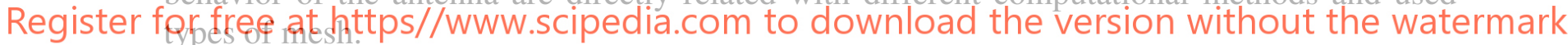

The antenna port position P240 seems to be less optimal than the P260. This is why all simulation models discussed in the following chapter will be related to the P260 position. The final location of the feeding port will be verified by additional measurements to be carried out on a fully enclosed winglet prototype. In any case, the impedance matching of the antenna can be further improved by matching circuits like L-C networks or via a balun.

\section{ANTENNA INSTALLED ON EV-55 AIRCRAFT}

\subsection{Radiation efficiency of installed antenna}

According to [2], the field strength of an airborne VHF antenna shall not be down more than $6 \mathrm{~dB}$ and vary more than $6 \mathrm{~dB}$ in comparison with a standard vertically polarized monopole antenna. Naturally, the radiation pattern of an installed antenna may differ with respect to a specific position on an airplane. Compared to the standard case when an antenna is installed on a fuselage (i.e. relatively uniform and large ground plane), this verification is especially important when it comes to the VHF antenna integrated inside a winglet. Therefore is useful to verify if the antenna is performing well at the place of its installation. 

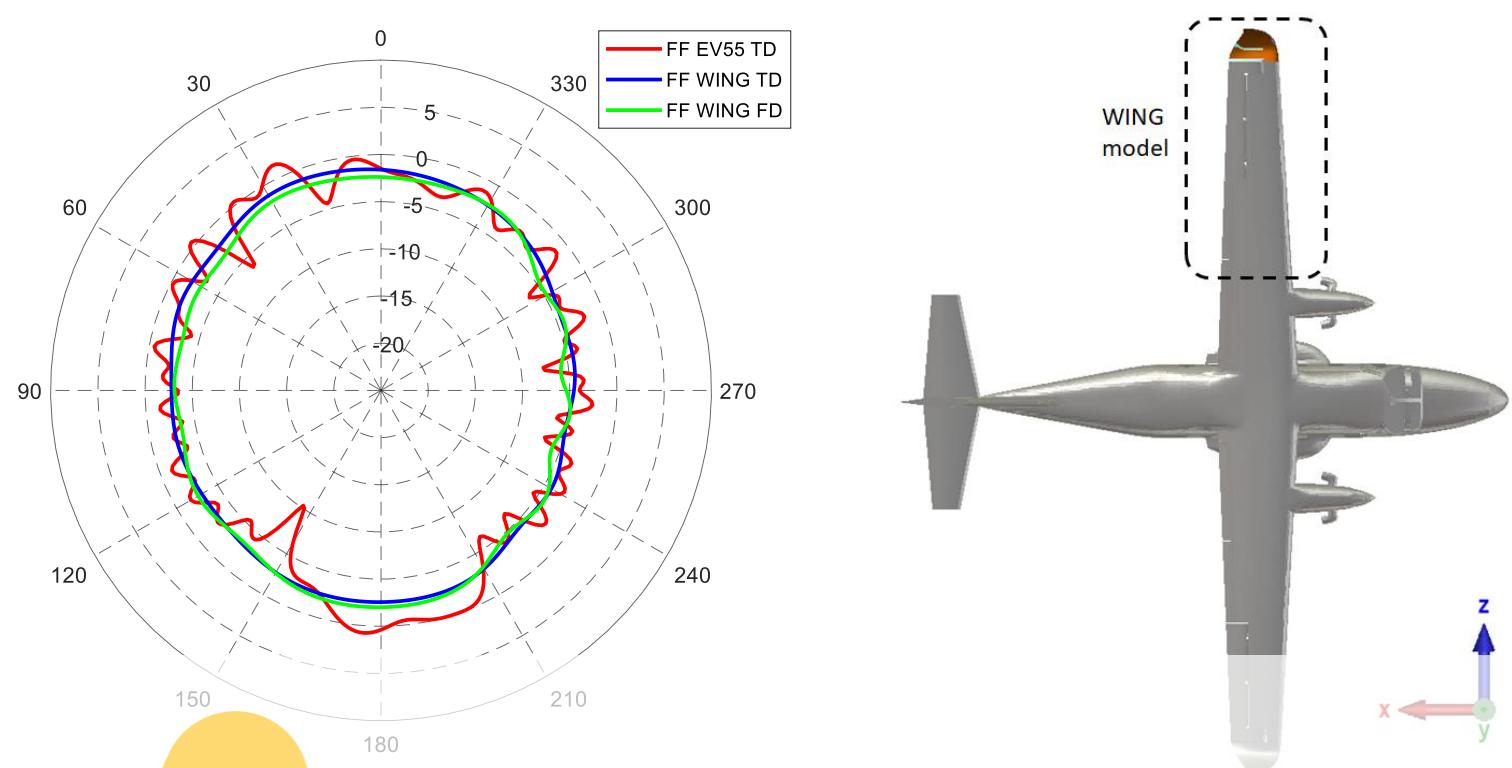

Figure 3: Antenna gain (vertical comp.) for different simulation scenarios $\left(\mathrm{Phi}=0^{\circ}\right.$, Theta $\left.=0^{\circ}-360^{\circ}\right)$ Table 1: Comparison of resulting gain parameters for different simulation scenarios
\begin{tabular}{|l|c|c|c}
\hline Model / solver: & Maximum [dBi] & Average [dBi] & Minimum [dBi]
\end{tabular}

\begin{tabular}{|c|c|c|c}
\hline EV-55/TD & 1.5 & -2.3 & -10.0 \\
\hline
\end{tabular}

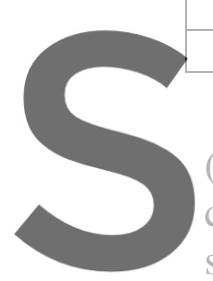

WING / T

WING / FD

Radiation efficiency

(full model of EV-55

computational methods

summarized in table Table
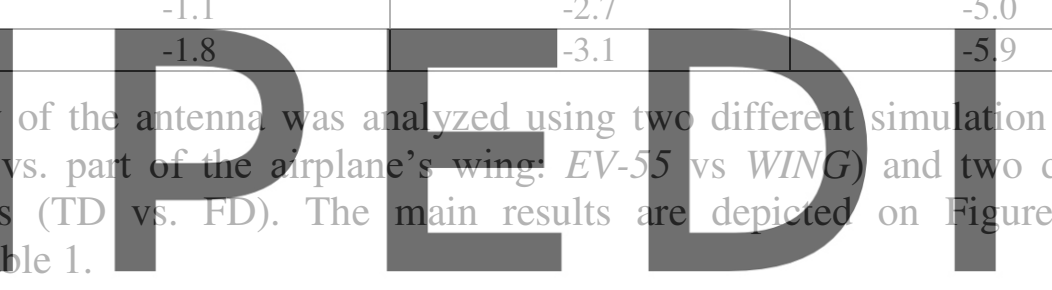

Current results indicates that the antenna is slightly underperforming with respect to the

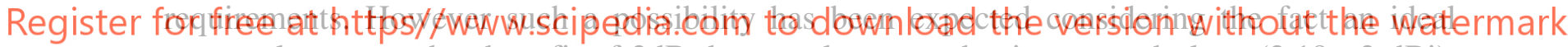
monopole antenna has benefit of $3 \mathrm{~dB}$ due to a large conductive ground plane $(2.19+3 \mathrm{dBi})$.

The requirement for the maximum field strength deviation is usually referred to the antenna prior its final installation on an airplane. Presented results indicate that this requirement can be fulfilled without significant problems (WING models).

In addition, further analyses on full-scale EV-55 model indicated that the antennas installed on both wings are decoupled. So it is possible to use diversity strategies to improve the system performance.

\subsection{Lightning strike protection}

Winglets represent one of the one most probable locations where a lightning strike can hit an airplane during a flight (Zone 1A, 1B). This is why the winglet antenna has to be designed and tested to more critical electromagnetic environments than is usual for ordinary VHF antennas installed on a fuselage (Zone 1A). The main protection against possible direct attachment of a lighting strike to the antenna is provided by the winglet structure and position of the antenna. The winglet has an integrated diverter strip going along the leading edge, from the tip of the winglet to the bottom part, where it is conductively connected to the metallic 
structure of a wing (see Figure 1). In addition, an expanded $\mathrm{Cu}$ metal foil is integrated into an outer layer of the winglet external CFRP shell to provide both an additional protection to the CFRP structure and to provide better route to a lightning channel passing across the surface during a lightning strike event.

In case of possible indirect effects of lightning, it is essential to determine approximate levels of voltage and current transients induced at the port of the antenna, along the whole VHF route, and neighboring systems that may interfere with the VHF system. In this paper, only $\mathrm{U}$ and I transients at the port of the antenna will be discussed (transients induced in cables and other electrical systems can be obtained in a similar way).

The basic concept of a simulation model that can be used for this kind of analyses is presented on Figure 4. The model does not address possible problems due to thermal damage, dielectric breakdown, arcing and sparking events. The EM source is represented by an ideal current source positioned at the tip of the winglet (the end of the diverter strip). The applied current waveform emulates a fist return stroke (Component A). [5]
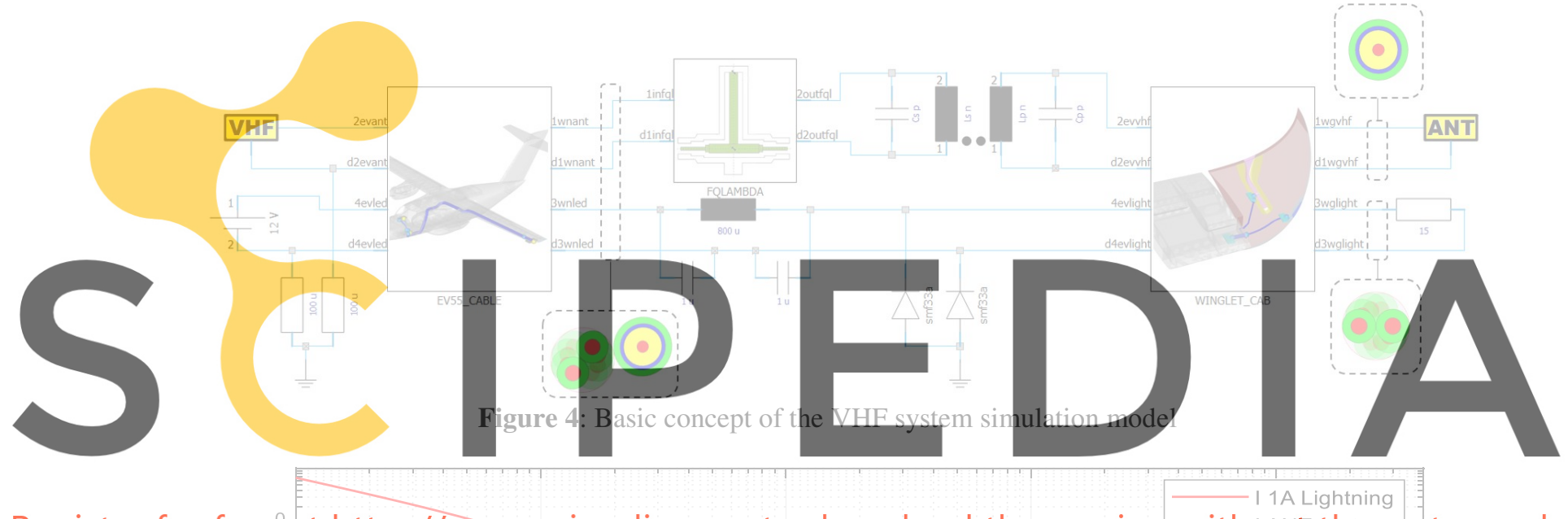

Register for free at https//WWw.scipedia.com to download the version withoutt thie watermark

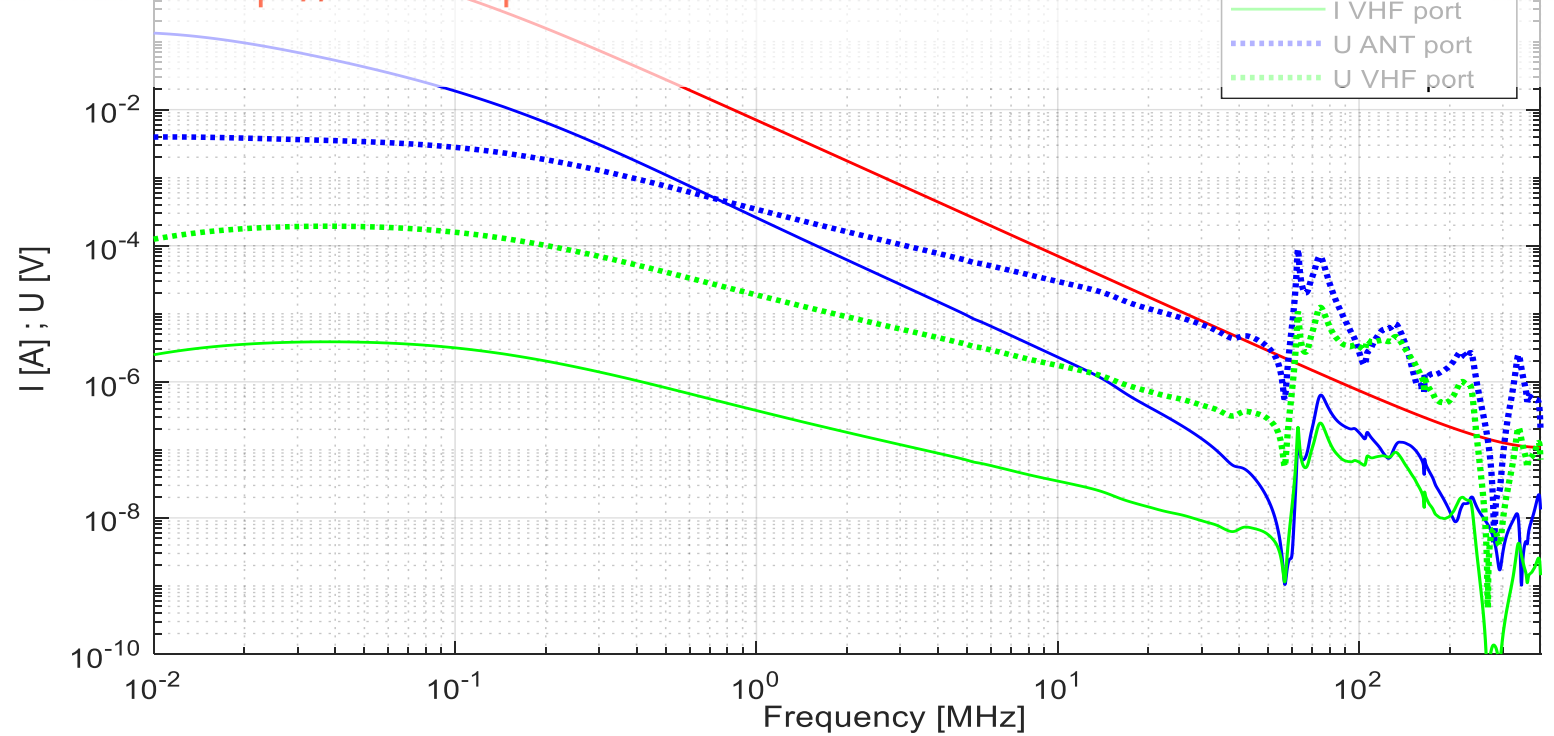

Figure 5: $\mathrm{U}$ and I transients at the antenna port and VHF transceiver input produced by lightning currents (current source: component A) passing through the winglet to the EV-55 wing structure 
Relatively high levels of currents can be seen at the antenna port at low frequencies (see Figure 5). Character of these disturbances will naturally change at the higher frequencies, where the antenna starts to resonate, thus voltage transients will become dominant due to increasing impedance at the port. Results indicate that lightning transients at the antenna port does not represent a significant problem when considering the basic protective circuitry introduced to the VHF line. Nevertheless, the VHF antenna represents only one part of the problem and other potential sources of EM disturbances have to be analyzed to obtain full picture of the system behavior.

\section{SUMMARY}

Simulated and measured reflection coefficients of the notch antenna for different scenarios are showing good antenna matching and sufficient bandwidth. Radiation efficiency of the antenna installed on the EV-55 airplane is not fully meeting the general requirements. However the reason is not due to bad performance of the antenna but due to the fact that these requirements are not taking into account similar scenarios / positions for installation of a VHF antenna. The antenna has a good potential for further adjustments with respect to its bandwidth and radiation characteristics. This will give us enough space for final adjustments of the antenna during the final stage of the prototype preparation, or at higher TRLs when solving possible performance deviations due to manufacturing inaccuracies or other changes.

The last part of the paper is discussing basic protection of the winglet with integrated VHF

antenna against directand indirect effects of lightning strike. We have presented the basic
simulation model for more detailed anglysis of lightning transients introduced to the VHF line
via the antenna element and determined their approximate levels.
Knowledge of resulting transient levels can help us to determine yhether the electronic
systems are sufficiently protected at the systen and sub-systern levels and establish the proper
lightning requirements for the whole VHF conmunication system at higher TRLs.

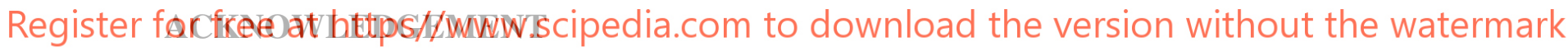

All work described in this paper has received funding from the European Union's Horizon 2020 research and innovation programme under grant agreement No 723167, ACASIAS project.

\section{REFERENCES}

[1] Advanced Concepts for Aero-Structures with Integrated Antennas and Sensors (ACASIAS), http://www.acasias-project.eu/

[2] RTCA DO-186B, Minimum Operational Performance Standards (MOPS) for Airborne Radio Communications Equipment Operating Within the Radio Frequency range $117.975-137.000 \mathrm{MHz}$

[3] M. Martínez-Vázquez, J. Balcells-Ventura, Z. Řezníček, K. Gonet, S. Steeger, P. Vrchota, V. Lungaho, VHF notch antenna integrated in an aircraft winglet, submitted to IEEE Antennas \& Propagation Society Symposium, Atlanta, US, 2019.R.

[4] A. Burberry, VHF and UHF antennas, IEE Electromagnetic series 36, Peter Peregrinus, 1992.

[5] SAE ARP5412A, Aircraft Lightning Environment and Related Test Waveforms, 2004 